\title{
Design of Angular Drilling Fixture and Analysis of Cutting Forces during Drill- ing on Cylindrical Surfaces
}

Nikhil G. Lokhande* and C.K. Tembhurkar

Department of Mechanical Engineering, G.H. Raisoni college of Engineering, Nagpur, India

\begin{abstract}
Applications such as in defense sector, manufacturing of grenade fuse required angular holes on fuse body, producing holes in turbine blades for the aerospace industry, generating micro-holes in diesel fuel injection nozzles etc requires angular drilling. Trepanning, gun drilling are the operations available for drilling at specific angle, but they can be useful when drilling angle should be less than 10 degree. The job having a cylindrical shape and number of holes are required on it at an angle is challenging task for design engineer and hence Computer Aided Fixture Design (CAFD) is incorporated in manufacturing industry. It deals with the integration of CAD and CNC programming in CAM systems using softwares for fixture design. Except $V$ block, no other option is available to hold cylindrical object and hence special type of fixture is designed for this case, which can be used for angular drilling. In this paper, a literature survey of computer aided fixture design and automation over the past decade is proposed. First, an introduction is given on the fixture applications in industry. Then, significant works done in the CAFD field, including their approaches and customer requirements are discussed.
\end{abstract}

Keywords: CAFD; Drilling fixture; Angular drilling; Drilling at specific angle

\section{Introduction}

Fixtures accurately locate and secure a part during machining operations such that the part can be manufactured to design specifications. To reduce design costs associated with fixturing, various Computeraided fixture design (CAFD) methods have been developed through the years to assist the fixture designer.

A key concern to a manufacturing company is the ability to manufacture high quality products in as short a time as possible. Quick release of a product into the market place, ahead of any competitors, is crucial to securing a higher percentage of the market place. Fixtures play an important role within many manufacturing processes. They accurately locate and secure a workpiece during machining such that the part can be manufactured to design specifications. Thus fixtures have a direct effect upon machining quality, productivity, and the cost of products.

Currently a software implementation of the CAFixD method is being developed as a stand-alone system that communicates with other $\mathrm{CAD} / \mathrm{CAM}$ packages as and when it needs to pass or receive information from external sources. The purpose of CAFixD is to process this information, use it to generate a fixture design, and then pass on the details of this fixture design to a CAD package that will create the fixture design drawings. System development is currently focusing on two main areas. The first is that the decomposition reconstitution approach results in the dynamic creation of constraints during the adaptation stage and these constraint effects must be incorporated into the evaluation of design adaptability. A simple example of this constraint generation is that checks must be performed to ensure that individual units are compatible with each other and can be combined to form a complete fixture. A second issue is the learning mechanism. This is a key area of development. Due to the high levels of computation involved in CAFixD, work is ongoing to develop strict criteria for managing the growth of the case base [1].

\section{Literature Review}

\section{Existing fixture design for drilling}

A drilling fixture for drilling either cylindrical or flat workpieces on or off center is disclosed. The fixture includes a base having v- shaped groove for receiving larger cylindrical workpieces, a pair of smaller $\mathrm{v}$ shaped openings in the side walls of the base for receiving smaller cylindrical workpieces, a cover attached to the base and a rotatable, indexable drill bushing mounted to the cover.

This invention relates to a drilling fixture for accurate positioning of drill bits and control of the direction during cylindrical shaped surfaces either on or off center. The drilling fixture locates the drill bits precisely with the spot to be drilled, maintains the drill in that location without wondering during the drilling operation weather drilling the curved or flat surfaces and maintains the alignment of drill throughout the drilling operation [2].

A tool is used for guiding and ensuring the correct position for cross drilling in a rod. Further tool will function as various types of work holders or tool holders. The tool is a cube with chamfered corners that form eighteen sided symmetrical polygon. Each side has bored holes therein arranged in an appropriate size and location to permit the tool to be used for its many functions.

This device consist of a one piece, uniformly square metal cube having all corners chamfered at a 45 degree angle to provide each corner with flat surface to yield an 18 sided symmetrical polygon. Seventeen of the side provided with bored holes of different sizes with each hole concentric and parallel to the center line of two opposite and parallel surface of the cube [3].

U.S. pat. No. 4,955,766 discloses the combination of drill bit with the stop collar and a fixture used for making pocket holes at an angle to

*Corresponding author: Nikhil G. Lokhande, Department of Mechanical Engineering, G.H. Raisoni college of Engineering, Nagpur, India, Email: nikhil.lokhande10@yahoo.in

Received April 05, 2012; Accepted April 28, 2012; Published April 30, 2012

Citation: Lokhande NG, Tembhurkar CK (2012) Design of Angular Drilling Fixture and Analysis of Cutting Forces during Drilling on Cylindrical Surfaces. J Appl Mech Eng 1:107. doi:10.4172/2168-9873.1000107

Copyright: (c) 2012 Lokhande NG, et al. This is an open-access article distributed under the terms of the Creative Commons Attribution License, which permits unrestricted use, distribution, and reproduction in any medium, provided the original author and source are credited. 
the surface of the workpiece. The fixture has L-shaped base with one leg serving as a guide portion for job and other portion holding a clamping device. An angled channel having a stop flange at its upper end is provided on guide portion leg. The drill bit inserted into channel and drills the hole at an angle upto the point where the stop collar engages the flange[4].

\section{Computer aided fixture design (CAFD)}

Intelligent techniques for CAFD: Typically, fixture design involves the identification of clamps, locators, and support points, and the selection of the corresponding fixture elements for their respective functions. There are four main stages within a fixture design processsetup planning (D1), fixture planning (D2), fixture unit design (D3) and verification (D4).Setup planning determines the number of setups required to perform all the manufacturing processes, the task for each setup, e.g., the ongoing manufacturing process and workpiece, orientation and position of the workpiece in each setup. A setup represents the combination of processes that can be performed on the workpiece by a single machine tool without having to change the position and orientation of the workpiece manually.

Fixture design still continues to be a major bottleneck in the promotion of current manufacturing. This work currently, is implemented by a typical designer-centered pattern, that is, all fixture design related work is heavily dependent on the experience and knowledge of fixture designer. This situation hampers the improvement of productivity, requires a long time to cultivate an experienced fixture designer and make the fixture design job weak with a major bottleneck. Thus, new intelligent or automatic technologies on synthesizing traditional geometric design tools, design knowledge, and past design cases have attracted much interest in both academic institutions and industries. The efforts over past decades in this field have resulted in numerous Computer Aided Fixture Design (CAFD) applications using various intelligent methods, such as expert system, case based reasoning, and Genetic Algorithm (GA), etc.

Recent achievements on some new knowledge related techniques, such as knowledge modeling, data mining, machine learning, and so on, indicate a more promising and fruitful future for the development of advanced computer aided fixture design. In many manufacturing companies, the technical knowledge of experienced fixture designers, a huge amount of technical files and many good design cases are a very valuable resource for fixture design. Using new technologies in the knowledge engineering field to refine model and utilize fixture design domain knowledge as an information base for intelligent and automatic systems can assist a fixture designer not only by simplifying the design process, but also by generating design ideas. For example, some interesting progress on using XML technology as a fixture knowledge representation tool to support case-based reasoning in the fixture design process is attractive, despite the reality that it need more effort on the systemization of intelligent techniques in fixture design.

Integrated Fixture Design System for Manufacturing : In essence, fixture design only is a partial process in manufacturing, and it should obey to the total objective of workpiece manufacturing requirements which often are related with production resources, equipment, cost and machining processes, etc. Therefore, it is necessary to put the fixture design task into an overall manufacturing process to obtain best fixture design solution.

CAFD systems with other manufacturing related technologies, even though many early researches are very limited in obtaining the manufacturing requirements from and send the result of fixture design to other systems, e.g. PDM or PLM systems. Future research should emphasize the importance of more efficient integration of fixture systems with other manufacturing systems. Particularly, view the fixture design as one node in a whole chain of manufacturing process. So we have to consider the impact of fixture design result on the cutting center and machining toolpath, and meanwhile, we also may find a necessary redesign of the fixture solution due to various conditions of cutting tools, production amount and cost, etc [5].

Challenges on angular drilling on cylindrical objects: With the advent of CNC machining technology and the capability of multi-axis machines to perform several operations and reduce the number of setups, the fixture design task has been somewhat simplified in terms of the number of fixtures which would need to be designed. However, there is a need to address the faster response and shorter lead-time required in designing and constructing new fixtures.

Problems occurring in today's scenario for drilling on cylindrical objects are:

- Drilling in various angles on curved body

- Unavailability of fixture for drilling at specific angles

- Poor repeatability and accuracy

There are not many fixtures available for drilling on cylindrical objects in today's scenario.

As application for drill fixture differs from industry to industry because dimensions required by industries differ from each other. Main requirement of customer is holes produced on fuse body should have high degree of accuracy and it is used for mass production. Also it can withstand stresses acting on it during operation and can run for long life. It is often a problem to the small workshop to machine surfaces which have to be turned, bored or faced at any angle other than a right angle to a primary base or reference surface. You may have to make or manage special fixtures to hold the work. A great deal depends on the size of the work and the stiffness of the mounting required to resist the machining load.

In some applications such as in defense sector manufacturing of grenade fuse required angular holes on fuse body, producing holes in turbine blades for the aerospace industry, generating micro-holes in diesel fuel injection nozzles etc requires angular drilling. In some applications if the hole to be drill is greater than 10 degree then it is very difficult to make hole in such object.

For mass production of above applications there is need to develop a drilling fixture which can make accurate holes at an angle with excellent repeatability and accuracy. Angular drilling on cylindrical surfaces is task which required skills, and if it will be performed without using Computer Numerical controlled machines, and it will be tedious process which takes lot of time.

\section{Development of fixture assembly for drilling at specific angle}

For making a fixture for angular drilling steps involved are:

- Analytical design for fixture

- 3 - D Modeling in PRO - ENGINEER Wildfire 5.0

- Assembly

- Analysis by using ANSYS

- Program generation by PRO - ENGINEER Wildfire 5

- Import a program to CNC Machine

For this project, it is very necessary to study every aspect of existing 
Citation: Lokhande NG, Tembhurkar CK (2012) Design of Angular Drilling Fixture and Analysis of Cutting Forces during Drilling on Cylindrical Surfaces. J Appl Mech Eng 1:107. doi:10.4172/2168-9873.1000107

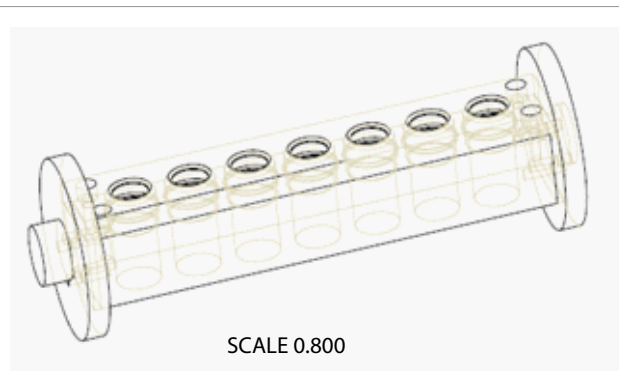

Figure 1: Drilling Fixture Assembly.

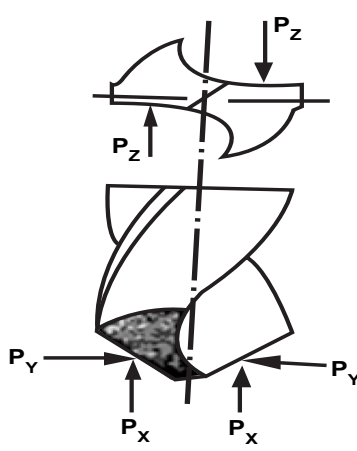

Figure 2: Twist drill showing cutting forces.

design of drilling fixture so that changes required can be easily define. Comparison of existing design with the proposed enables us to find correct way of design (Figure 1).

Approach to fixture design:

- Analysis of the work piece drawing

- Identification of candidate elements (machined surfaces for locating, possible clamps positions, important regions of workpiece, tool path, possible tool interference points, etc.)

- Support, location, clamping, base, guiding, fasteners taken in consideration

- Methodology (modular, vice, v-block, point surface, angular structure, multiworkpiece clamping, 3-2-1 principle etc.)

- Identification of solutions (successful sequence of local solutions and creation of a consistent solution, selection of a pattern for modular fixtures (positioning of 2 or more workpieces)

- Fixture design

- Building of assembly

Functions of parts:-

Square block: It is used to hold cylindrical objects and can rotate at particular angle with supporting plates. It acts as locator for work pieces.

Left hand and Right hand circular plate: It is used for locating and supporting a square block.

The main purpose of providing these plates is to adjust square block at any angle, and drilling can be done accurately.

\section{Analysis of cutting forces in drilling}

Drill is subjected to action of cutting force, which can be conveniently resolved into three components (Figure 2):
- Tangential $(\mathrm{Pz})$

- Axial (Px)

- Radial (Py)

Data:

Drill rpm $=1200$

Diameter of drill $=5 \mathrm{~mm}$

Feed $=0.1 \mathrm{~mm} / \mathrm{rev}$.

Type of drill $=$ Twist drill

Power $(\mathrm{KW})=1.25 \mathrm{~d}^{2} \mathrm{~K} 1 \mathrm{n}(0.056+1.5 \mathrm{~s})$

$10^{5}$

Where,

$\mathrm{K} 1=$ Material factor for brass (1.5)

$\mathrm{d}=$ Dia of drill

$\mathrm{s}=$ Feed $\mathrm{mm} / \mathrm{rev}$

$\mathrm{n}=\mathrm{RPM}$ of drill [6]

Thrust $(\mathrm{kgf})=1.16 \mathrm{~K} 1^{*} \mathrm{~d}^{*}(100 \mathrm{~s})^{0.85}$

$\mathrm{Ks}=\mathrm{Pz} / \mathrm{A}$

Where,

Ks $=$ cutting force $=\left(1.5^{\star} 0.1\right)$

$\mathrm{Pz}=$ force acting on each lip in kgf

$\mathrm{A}=\mathrm{Ds} / 4$

Torque $(\mathrm{M})=\mathrm{Pz}^{\star} \mathrm{d} / 20$

\section{Result}

Power $=0.1158 \mathrm{kw}$

Thrust $=61.59 \mathrm{kgf}$

$\mathrm{P}(\mathrm{z})=0.0187 \mathrm{kgf}$

Torque $=4.67$ e $10^{-3} \mathrm{~kg} \cdot \mathrm{mm}$

Analyzing the drill for $0.183 \mathrm{~N}$ by using Ansys Workbench 12(Figures 3,4 )

Steps of Analysis:

- Import model in IGES format in Ansys workbench 12

- Divide the model in elements by meshing

- Apply the force

- Solve for stress calculation

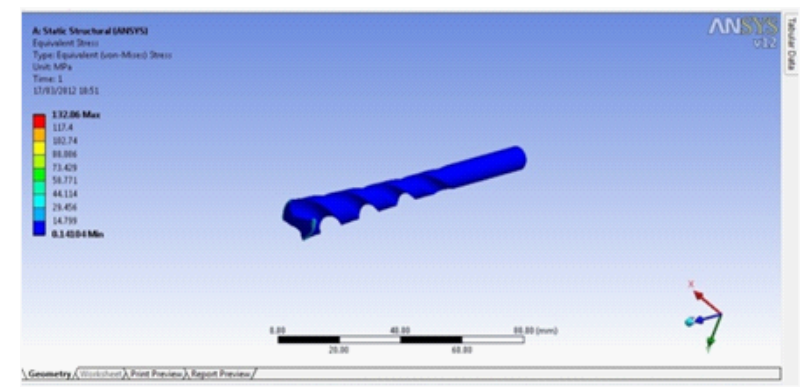

Figure 3: Shear Stress Analysis of Drill by ANSYS. 
Citation: Lokhande NG, Tembhurkar CK (2012) Design of Angular Drilling Fixture and Analysis of Cutting Forces during Drilling on Cylindrical Surfaces. J Appl Mech Eng 1:107. doi:10.4172/2168-9873.1000107

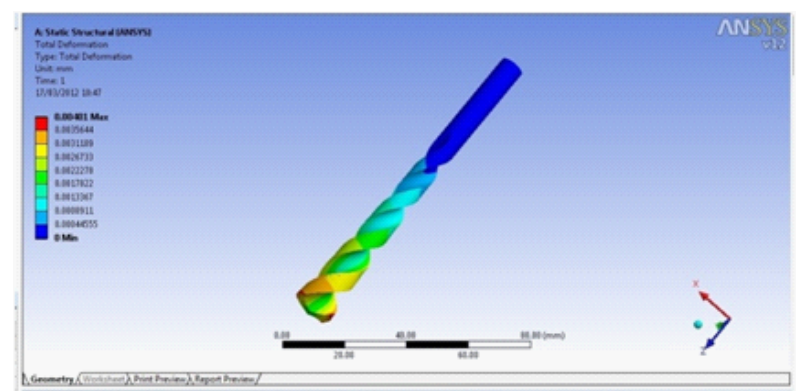

Figure 4: Static structural Deformation.

\begin{tabular}{|l|l|l|}
\hline Parameters & Analytical & ANSYS \\
\hline Deflection in mm & 0.052 & 0.00401 \\
\hline Von mises stress in MPa & 110.23 & 132.06 \\
\hline $\begin{array}{l}\text { Maximum shear stress in } \\
\mathrm{MPa}\end{array}$ & 69.26 & 75.551 \\
\hline
\end{tabular}

Table 1: Comparison between analytical calculation of cutting forces and ANSYS.

\section{Conclusion}

There are not many fixtures available for angular drilling in today's scenario. As application for fixture design differs from industry to industry because dimensions required by industries differ from each other. This simple design of drilling fixture assembly enables to perform such operation with accuracy and repeatability by attaching U- CAM 4th axis attachment on Vertical Machining Center (VMC).

After analyzing the drill by Finite element method by considering axis symmetric loading, the results obtained are validating with Ansys results. Problems involving three dimensional axis symmetric solids subjected to axis symmetric loading reduce to two dimensional problems. Because of total symmetry about $\mathrm{z}$ axis all deformations and stresses are independent of rotational angle. Thus, the problem needs to be looked at as two-dimensional problem (Table 1).

The cutting forces and torque are much lower when drilling on brass. Therefore negligible amount of stress and deformation takes place while operation.

\section{References}

1. Boyle IM, Rong K, Brown DC (2006) "CAFixD: A Case-Based Reasoning Fixture design method. Framework and Indexing Mechanisms". J Comput Inf Sci Eng 6: 40 .

2. klee G, De Noma GR, Collier SL, Newman RJ (1984) Drilling fixture

3. Robert L. Reynolds (1987) Drilling fixture and work holder. United states patent

4. Burton Weinstein, Richard H. Deaton (2001) Fixture for drilling pocket holes United States patent.

5. Hui Wang, Yiming (Kevin) Ronga, Hua Li, Price Shaun (2010) Computer aided fixture design: Recent research and trends. Computer-Aided Design 42: 10851094.

6. (1980) Handbook on Production technology. HMT Banglore published, Tata McGraw hill. 